\title{
ESTUDO DO REAPROVEITAMENTO DO GÁS DE TOPO DE ALTO-FORNO A CARVÃO VEGETAL PARA REDUÇÃO DO FENÔMENO DE CREPITAÇÃO EM GRANULADOS DE MINÉRIO DE FERRO
}

\author{
Leonardo Neves ' \\ Ricardo Luiz Perez Teixeira ${ }^{2}$ \\ Leonardo Lúcio de Araújo Gouveia ${ }^{3}$
}

Resumo

O fenômeno de crepitação de minérios de ferro ocorre durante o processo de redução do minério de ferro em altos-fornos e é uma fonte geradora de finos devido à sua degradação granulométrica. Os finos em excesso prejudicam a permeabilidade da carga e diminui o rendimento da produção de ferro-gusa. No presente trabalho, foi realizado um estudo da crepitação de minérios de ferro através do emprego de um sistema de pré-tratamento térmico do minério de ferro a partir do gás de topo no processo de produção de ferro-gusa de um mini alto-forno a carvão vegetal em uma empresa situada de Minas Gerais. Foram utilizados dois períodos de sete dias cada, sendo que no primeiro período o sistema de pré-tratamento do minério estava desativado e no segundo o sistema foi ativado. Os resultados demonstraram uma melhora nas propriedades do minério de ferro quando se utiliza o pré-tratamento com o gás de topo, pois resultou num aumento de produção por amenizar o fenômeno de crepitação.

Palavras-chave: Gases de exaustão; Alto-forno; Crepitação do minério de ferro; Pré-aquecimento da matéria-prima.

\section{STUDY TO REUSE OF THE EXHAUST GASES OF THE BLAST FURNACE TO REDUCE THE DECREPITATION IN IRON ORE GRANULES}

\begin{abstract}
The phenomenon of particle size degradation of minerals due to decreptation is presented as source of fines. In the present work, a study of iron ores decrepitation by employing a system of thermal pretreatment of iron ore was carried out reusing exhaust gases from a mini charcoal blast furnace located in the state of Minas Gerais. The experiments were carried out in two periods of seven days each one, where in the first period the pretreatment system was deactivated and in the second period was activated. The results showed an improvement in the burden permeability by the reduction of the granules decreptation when it was used the thermal pretreatment, reflecting in a increasing of production.
\end{abstract}

Keywords: Exhaust gases; Blast furnace; Iron ore decreptation; Raw material preheating.

\section{INTRODUÇÃO}

O fenômeno de degradação granulométrica de minérios, que ocorre durante o aquecimento, é denominado crepitação, o mesmo se apresenta como uma fonte geradora de finos, que em excesso prejudica a permeabilidade da carga. O primeiro a estudar este fenômeno foi Birnbaum [ $I$ ], na década de 1960. Uma das primeiras hipóteses é que a crepitação está associada à vaporização brusca de água contida nos poros dos minérios. Segundo o autor, a degradação granulométrica só ocorreria em amostras úmidas, apesar do fato de existirem minérios que mesmo úmidos não apresentam o fenômeno de acordo com Kunii et al. [2] a água de cristalização foi o fator responsável pela crepitação de alguns dos minérios utilizados. A pressão de vapor, resultante da decomposição de fases minerais hidratadas, principalmente da goethita, gera tensões suficientemente grandes para romper o minério, e, que depende dos tipos

\footnotetext{
'Centro Federal de Educação Tecnológica de Minas Gerais - CEFET-MG, Belo Horizonte, MG, Brasil. E-mail: prof.leonardoneves@gmail.com.

'Universidade Federal de Itajubá - UNIFEI, Itabira, MG, Brasil.

${ }^{3}$ Universidade do Estado de Minas Gerais - UEMG, João Monlevade, MG, Brasil.
} 
de poros. De acordo com Faria [3] a crepitação de minérios de ferro é uma característica metalúrgica frequentemente considerada para fins de controle de qualidade de cargas de altos-fornos, visto que a degradação granulométrica do minério é indesejada no processo de redução. A crepitação ocorre uma única vez em cada partícula de minério de ferro, de forma que, uma vez submetida a um choque térmico ou pré-tratamento térmico, caso experimente outros, não será verificada uma nova degradação granulométrica. Vários estudos [4-6] têm descrito a importância da secagem e tratamento térmico de granulados de minério de ferro para uso em reatores de redução. Uma das alternativas para de secagem é utilizando o gás de topo do alto-forno, sendo este um coproduto da produção do ferro-gusa, tem alto poder calorífico e não é utilizado em sua totalidade, sendo sua maior parte queimada e liberada na atmosfera. Estudos sobre o balanço energético da Companhia Energética de Minas Gerais [7] mostraram que o volume total de gases gerados nos altos-fornos e fornos elétricos de redução instalados em Minas Gerais correspondeu, em 2009, a I.67I mil Toneladas Equivalentes de Petróleo (TEP). Esse valor representou $5,3 \%$ da demanda total de energia do Estado de Minas Gerais, da ordem de grandeza do consumo total de eletricidade do setor Industrial. No presente trabalho foi utilizado um mecanismo de secagem e tratamento térmico de granulados desenvolvida por Vieira et al. [8], denominada tecnologia JB (iniciais do autor) já empregada em usinas brasileiras. Desta forma o estudo visa a utilização do gás de topo do alto-forno como uma forma de reduzir o fenômeno de crepitação do minério de ferro.

\section{METODOLOGIA}

Para o cálculo do índice de crepitação foram feitos ensaios de acordo com a norma ISO/CD 873I-04 [9]. Foram feitas análises em dois tipos de minérios de ferro utilizados no processo de redução. Após as amostras terem sido coletadas, foram feitas análises nas propriedades físicas quando submetidas à temperatura de $700^{\circ} \mathrm{C}$. Tais amostras foram retiradas direto do silo de alimentação antes de serem enfornadas. A norma ISO/CD 873 I-04, segue os seguintes procedimentos: a amostragem possui a massa de $500 \mathrm{~g}$ de minério de ferro entre $20 \mathrm{~mm}$ e $25 \mathrm{~mm}$; a secagem desse material é feita a $105 \pm 5{ }^{\circ} \mathrm{C}$ e peneiradas em $20 \mathrm{~mm}$ para eliminação dos finos; As alíquotas são depositadas em fornos tipo mufla a $700{ }^{\circ} \mathrm{C}$ onde permanecem por 30 minutos. Depois de resfriadas ao ar, as alíquotas são individualmente peneiradas nas malhas de $6,3 \mathrm{~mm}, 3,35 \mathrm{~mm}$ e $0,6 \mathrm{~mm}$. No atual estudo, o índice de crepitação foi determinado por meio da média aritmética das porcentagens em massa de material abaixo de 6,3 mm, 3,35 mm e 0,6 mm, respectivamente. As Equações I a 3 são utilizadas para o cálculo da média aritmética destas análises.

$$
I_{6,3}=100 \frac{m_{1}{ }^{(6,3)}}{m_{2}{ }^{(6,3)}}
$$

$$
\begin{gathered}
I_{3,35}=100 \frac{m_{1}^{(3,35)}}{m_{2}^{(3,35)}} \\
I_{0,6}=100 \frac{m_{1}^{(0,6)}}{m_{2}^{(0,6)}}
\end{gathered}
$$

As variáveis $m_{2}{ }^{(6,3)}, m_{2}{ }^{(3,35)}$ e $m_{2}{ }^{(0,6)}$ são as massas totais de material utilizadas em cada em ensaio. As variáveis $m_{1}{ }^{(6,3)}$, $m_{1}^{(3,35)}$ e $m_{1}{ }_{1}^{(0,6)}$ são as massas totais de cada alíquota após o choque térmico abaixo de $6,3 \mathrm{~mm}, 3,35 \mathrm{~mm}$ e $0,6 \mathrm{~mm}$, respectivamente $A$ variável $m_{1}$ é a massa total da alíquota após o choque térmico. Baseado nos estudos de Vieira [10] e em dados coletados da empresa foram feitos levantamentos da economia pelos benefícios gerados pelo mecanismo de pré-secagem e pré-aquecimento do minério de ferro. A composição química das matérias-primas utilizadas no proceso de redução no alto-forno é apresentada na Tabela $I$.

A técnica de pré-tratamento do minério de ferro considera $\circ$ silo de estocagem de matérias-primas como um reator metalúrgico com a função de pré-secagem dos granulados. Tal tecnologia consiste em empregar no silo gases quentes gerados pela planta no sentido ascendente vertical em contracorrente com a carga sólida no sentido descendente. $O$ estudo foi realizado em uma siderúrgica mineira localizada em Sete Lagoas no estado de Minas Gerais. Para analisar a eficiência do secador de minério foi observada a permeabilidade da carga utilizada no alto-forno em relação aos dados industriais de produtividade do alto-forno no período de sete dias com o mecanismo de secagem desativado e sete dias ativado. Além disso, análises do índice de crepitação foram feitas nos dois períodos.

A permeabilidade é um índice que quantifica a facilidade de escoamento dos gases pelo corpo do alto-forno. A Equação 4 representa a fórmula matemática utilizada [I I].

$$
P_{c}=\frac{V_{g}}{\left(P_{s}-P_{t}\right)}
$$

Em que:

$P_{c}=$ permeabilidade da carga $\left(\mathrm{Nm}^{3} / \mathrm{h} . \mathrm{atm}\right)$;

$V_{g}=$ volume de gás que atravessa o forno por unidade de tempo $\left(\mathrm{Nm}^{3} / \mathrm{h}\right)$;

$P_{s}=$ pressão do ar no alto-forno (atm);

$P_{t}^{s}=$ pressão do gás no topo do alto-forno (atm).

\section{RESULTADOS E DISCUSSÃO}

A crepitação do minério de ferro quando ocorre no interior do alto-forno possui uma relação direta com a produtividade por afetar diretamente a permeabilidade da carga. A Tabela 2 apresenta os resultados encontrados dos índices de crepitação dos minérios de ferro $A$ e $B$ amostrados nos silos para os dois períodos analisados.

Pela análise dos diferentes índices de crepitação, a geração de finos para as diferentes granulometrias diminuiu quando o sistema estava ativo. A geração de finos muitas 
Tabela I. Análise de matéria prima em \% em peso (Dados coletados de 2013)

\begin{tabular}{cccccccc}
\hline $\begin{array}{c}\text { Matéria } \\
\text { Prima }\end{array}$ & $\% \mathrm{Fe}$ & \%SiO $_{2}$ & \%Al $_{\mathbf{2}} \mathbf{O}_{3}$ & \%CaO.MgO & \%Mn & \%P & \%total \\
\hline Minério A & 60,54 & 7,12 & 2,16 & -- & 0,10 & 0,064 & 40,00 \\
Minério B & 60,72 & 6,38 & 2,13 & - & 0,05 & 0,069 \\
Briquete & 72,00 & 3,52 & 0,30 & 7,89 & 0,78 & 0,110 & 40,00 \\
Calcário & - & 1,32 & - & 51,89 & - & - & - \\
Sílica & - & 95,00 & - & - & - & - & - \\
Sucata & 60,00 & 3,00 & 2,00 & 15,00 & - & 20,00 & - \\
\hline
\end{tabular}

Tabela 2. Índice de crepitação amostra sem tratamento térmico

\begin{tabular}{ccccc}
\hline Índice de & \multicolumn{2}{c}{ I $^{\circ}$ Período (Desativado) } & \multicolumn{2}{c}{$\mathbf{2}^{\circ}$ Período (Ativado) } \\
\cline { 2 - 5 } Crepitação & Minério A & Minério B & Minério A & Minério B \\
\hline$I_{6,3}(\%)$ & 6,9 & 5,8 & $4, I$ & 3,9 \\
$I_{3,35}(\%)$ & 3,7 & 3,3 & 2,2 & 2,0 \\
$I_{0,6}(\%)$ & 1,2 & 0,6 & 0,6 & 0,5 \\
\hline
\end{tabular}

vezes pode ser relacionada com um alívio de tensões no interior do grão de minério de ferro quando se utiliza o pré-aquecimento e a pré-secagem, resultando na crepitação do minério no silo de alimentação, que porventura, ocorreria no interior no alto-forno.

O acompanhamento dos dados industriais durante as análises técnicas permitiram comparar a influência da crepitação com a permeabilidade e a produtividade em dois períodos distintos de sete dias cada. No primeiro período o sistema estava desativado e no segundo período ativado. Um fator importante e que tem grande influência no ritmo de produção é a permeabilidade da carga. Ela é responsável pela passagem do gás redutor em contra corrente com a carga descendente no interior do alto-forno. Quando há uma grande geração de finos, a permeabilidade do alto-forno fica comprometida, diminuindo o ritmo da produção. $O$ alto-forno em que foram feitas as análises tem como meta de produção um valor acima de 310 toneladas diária. A Figura I mostra a relação entre a produtividade e permeabilidade da carga no primeiro período em que foram feitas as análises com o sistema de secagem desligado. É possível verificar que a análise da permeabilidade acompanhou a produção diária no primeiro período em análise. O ritmo de produção é bastante sensível à permeabilidade.

$\mathrm{Na}$ Figura 2 refere-se ao segundo período de análises quando o sistema de pré-tratamento estava ativo e também nota-se a grande influência da permeabilidade na produtividade diária.

Ao se comparar as Figuras I e 2, nota-se que durante - $1^{\circ}$ período a produtividade diária esteve na maior parte dos dias abaixo da meta e que no $2^{\circ}$ período a produtividade diária esteve acima da meta. Isto se dá pois no $1^{\circ}$ período o minério atingiu as temperaturas de $500{ }^{\circ} \mathrm{C}$ a $700{ }^{\circ} \mathrm{C}$ dentro do reator crepitando em seu interior, gerando finos e consequentemente diminuindo o fluxo de gás redutor responsável pela eficiência do processo de redução. O

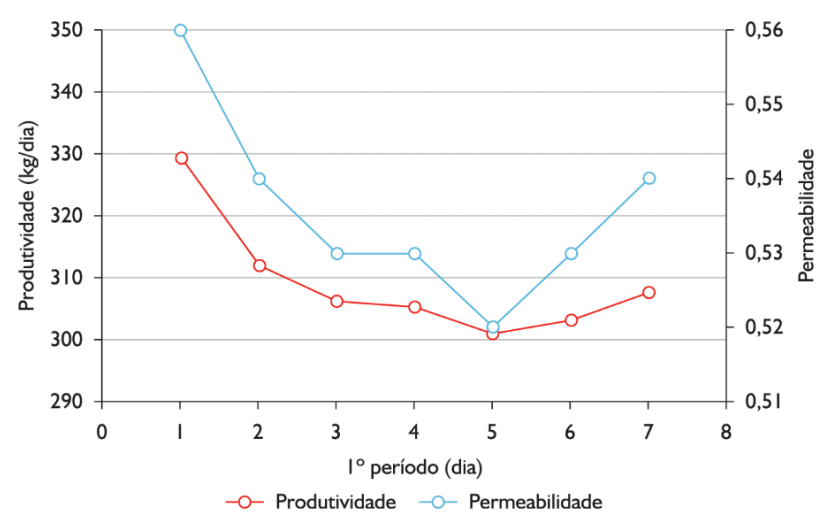

Figura I. Produtividade diária versus permeabilidade durante o primeiro período de análises.

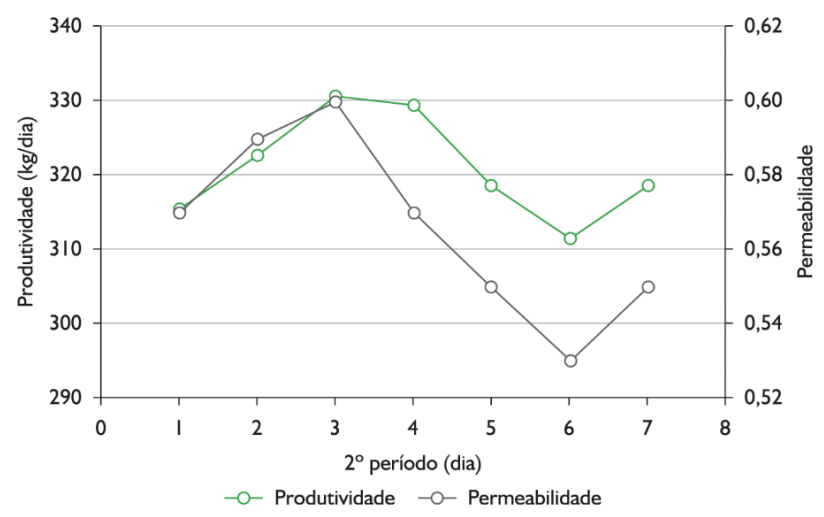

Figura 2. Produtividade diária versus permeabilidade durante 0 segundo período de análises.

tratamento térmico permitiu que a crepitação ocorresse no silo permitindo a separação dos finos antes da carga metálica ser enfornada possibilitando um aumento da eficiência na produção. Além disso, o minério de ferro é pré-aquecido, 
aumentando o aporte térmico diminuindo o gasto energético. Desta forma, o gás de topo utilizado no sistema tem como objetivo a pré-secagem e pré-aquecimento da carga metálica. Isto permite minimizar o fenômeno de crepitação no interior do alto-forno otimizando o fluxo gasoso em seu interior. A Figura 3 mostra uma comparação entre a produtividade dos dois períodos analisados. As médias de produtividade diária foram 309,25 I toneladas e 32 I , I 26 toneladas para o $1^{\circ}$ e $2^{\circ}$ período, respectivamente. Isto demonstra a maior produtividade no $2^{\circ}$ período em que o sistema estava ativo.

Com o tratamento de secagem e após peneiramento, evita-se que estes finos sejam enfornados, os quais interfeririam negativamente no escoamento gasoso, diminuindo a permeabilidade e consequentemente a produção. A utilização do mecanismo de secagem do minério de ferro pelo gás de topo permitiu a otimização energética do processo siderúrgico pelo reaproveitamento do gás de topo do alto-forno como energia no pré-aquecimento das matérias primas, reduzindo o fenômeno de crepitação do minério de ferro. Os ganhos da utilização do sistema podem ser feitos por uma análise econômica simples dos resultados apresentados. Durante o $1^{\circ}$ período a produção total foi de 2164,76 toneladas de ferro-gusa enquanto que para 0 $2^{\circ}$ período foi de 2247,88 toneladas de ferro-gusa. Logo o ganho no $2^{\circ}$ período foi de 83,12 toneladas. Considerando que $\circ$ valor de venda da tonelada métrica de ferro-gusa em meados do ano de 2013 (ocasião da pesquisa) era por

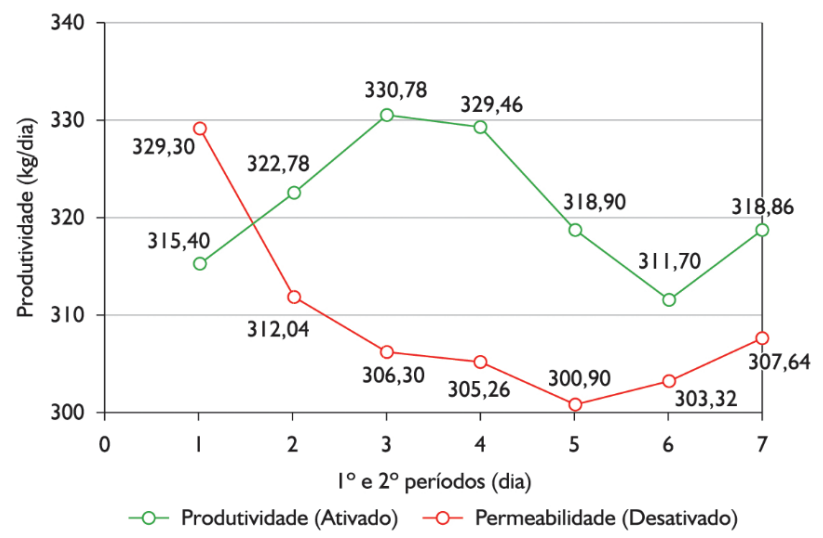

Figura 3. Produtividade diária do alto-forno nos dois períodos de análise. volta de US\$380,00 (diário do comércio [12]), o ganho adicional obtido quando o sistema de secagem estava ativo foi de US\$3I.585,00. Considerando o caso hipotético de estagnação do preço de venda do ferro-gusa durante um ano o ganho seria de US\$ I.5 I6.108,80. Sabe-se hoje que com a melhora no preço do gusa, o preço de venda está por volta de US $\$ 500,00$. Projetando os ganhos para os valores atuais o lucro anual seria de US\$ I.994.880,00. Além disso, considerando o baixo custo de manutenção, que não foi utilizada nenhuma matéria-prima adicional e que os finos gerados podem ser comercializados, o sistema de pré-tratamento de minérios de ferro é viável por promover melhoras no rendimento da empresa. Esta análise é apenas uma projeção e seria necessário uma análise mais completa em relação à mão-de-obra, perdas e custos de montagem do sistema de pré-tratamento térmico.

\section{CONCLUSÃO}

A utilização do sistema de secagem pelo aproveitamento do gás de topo como um método de pré-tratamento térmico do minério de ferro, possibilitou uma melhora no índice de crepitação. Os dados de análises industriais e de ensaios demonstraram de forma comparativa que quando se utilizou o sistema de secagem ocorreu uma melhora na permeabilidade no interior do alto-forno e consequentemente uma melhora na produtividade do reator. Comparando os períodos nos quais foram feitas as análises, nota-se que o emprego do sistema de secagem, a empresa produziu $98,980 \mathrm{~kg}$ de ferro-gusa a mais do que no período que o mecanismo estava desativado. Totalizando um ganho excedente de US\$3 1.585,00. Desta forma pode se afirmar que o gás de topo, co-produto do processo de fabricação do ferro-gusa, apresenta viabilidade econômica para implantação como meio de otimização do processo amenizador do fenômeno de crepitação.

\section{Agradecimentos}

Os autores são gratos ao Conselho Nacional de Desenvolvimento Cientifico e Tecnológico-CNPq pelo apoio à esta pesquisa.

\section{REFERÊNCIAS}

I Birnbaum $\mathrm{H}$. Essais sur minerais em morceaux em vue de la determination de leur comportament au haut fourneau. CIT. 1960;(10):2069-2089.

2 Kunii K. A Study on the decrepitation of iron ores. Testsu-to-Hagané. 1966;52(3):228-230.

3 Faria GL. Estudo da intensidade de crepitação de minérios granulados de manganês do Brasil [dissertação de mestrado]. Ouro Preto: Universidade Federal de Ouro Preto; 2008.

4 Abrão GS, Marinho FAM. Influência do sistema de drenagem de base no fluxo de água em pilhas de minério de ferro. In: Anais do $5^{\circ}$ Simpósio Brasileiro de solos não saturados; 2004 Ago. 25-27; São Carlos, Brasil. São Paulo: SGS/EESC/USP; 2004. p. 2 I I-2I6. 
5 Ferreira JC. Estudos sobre drenagem e redução de umidade do minério de ferro de carajás com a ut $<j r n></$ jrn>ilização de geossintéticos [dissertação de mestrado]. Brasília: Universidade de Brasília; 2009.

6 Strezov V, Evans T], Zymla V, Strezov L. Structural deterioration of iron ore particles during thermal processing. International Journal of Mineral Processing. 20I I; I00(I-2):27-32. http://dx.doi.org/10.10 I6/j.minpro.20I I.04.005.

7 CEMIG. Alternativas energéticas [página da internet]. [acesso em 20 jul. 20I4]. Disponível em: http://www.cemig. com.br/pt-br/A_Cemig_e_o_Futuro/inovacao/Alternativas_Energeticas/Paginas/default.aspx.

8 Vieira CB, Krüger FL, Araújo FGS, Vieira JB. Secagem e tratamento térmico de granulados de minérios de ferro para uso em reatores de redução: aplicação em usinas siderúrgicas brasileiras. In: 6th IAS Ironmaking Conference; 2007; Rosário, Argentina. San Nicolás: IAS; 2007.

9 International Organization for Standardization - ISO. ISO/CD 873I: iron ores for blast furnace feedstocks: determination of the decrepitation index. ISO/TC I02/SC3. Geneva; 2004.

10 Vieira CB. Estudo básico da qualidade intrínseca de minérios de ferro para altos fornos [tese de doutorado]. Belo Horizonte: Universidade Federal de Minas Gerais; 1996.

I I Araújo LA. Manual de siderurgia. São Paulo: Arte \& Ciência; 1997. (vol. 2).

12 Tomaz R. Setor de ferro-gusa está mais otimista. Diário do Comércio. 2014 Fev. [acesso em 17 ago. 2014]. Disponível em: http://www.diariodocomercio.com.br/noticia.php?tit=setor_de_ferro-gusa_esta_mais_ otimista\&id $=130074$.

Recebido em: 23 Ago. 2014

Aceito em: 4 Fev. 2015 